\title{
An Analysis about Reinforcement Effect in Permafrost Preloading Region
}

\author{
MA Xi-lei, ${ }^{1, a}$, SHEN Xiao-ming ${ }^{1}$,WANG Hua-luan ${ }^{1}$ \\ ${ }^{1}$ Tianjin Research Institute for Water Transport Engineering, Tianjin, China \\ amaxilei1984@163.com
}

\begin{abstract}
Keywords: Permafrost region, Preloading, Freezing-thawing cycle, Settlement law
Abstract. This study is based on an actual preloading project of permafrost region in Dalian, China. In order to obtain the testing results and reflect the reinforcement effect of this project, there are some preparations that are needed to be carried out, such as field monitoring, data analysis and so on. According to the testing results, the conclusion is obtained about that the physical and mechanical properties of the foundation after reinforcement and shear strength are significantly improved, the average degree of consolidation of the foundation reach more than $85 \%$, and the effect of foundation reinforcement is more ideal. So it comes to a conclusion that it is feasible to use the preloading method to reinforce the soft soil foundation of permafrost region and it can provide a good reference to the similar projects.
\end{abstract}

\section{Introduction}

With the rapid development of eastern coastal areas, the shortage of land resources in the city has been increasingly prominent, and the land has been unable to satisfy the requirements of the rapid development of the city, so the reclamation becomes an important way to solve the shortage of land resources in the coastal city, the method of hydraulic fill has been widely applied in the recent reclamation project. However, this method will make the surface of soft foundation fill with silty soil, and the construction of road, building and other facilities has to be carried out on this foundation. And it's difficult for the just completed dredger fill to get fully consolidated in the first few years, what's more, it has some features which are not beneficial to the working, such as high water content, high porosity ratio, high compressibility, low bearing capacity and so on. Because Dalian is a region with a lower temperature in winter, and it's located in seasonal frozen soil regions, the method of hydraulic fill has been hardly used in Dalian, besides there aren't mature experiences in dealing with the filled foundation. So in this project, adopting surcharge preloading to reinforce the hydraulic filled permafrost region in Dalian belongs to a new attempt, and it is of important guiding significance.

Based on testing engineering of dealing with the soft foundation at construction sites of Dalian Ocean University New Campus in China, this article adopts surcharge preloading to reinforce the foundation of testing area and combines with the monitoring to get the data at first, then analyze the data to validate the feasibility of surcharge preloading to consolidate soft foundation in this region, finally, provide design reference and experience to the similar projects in this region.

\section{Project Profile}

This project that deals with the soft foundation at construction sites of Dalian ocean university new campus is located at the south bank of Bohai bay of Liaodong peninsula in China. The landforms of test sites are sea plain and mountain sloping fields, the test zone of project is a $60 \mathrm{~m} *$ $80 \mathrm{~m}$ rectangular space, and the total area is $4800 \mathrm{~m} 2$, and the schematic plan of test zone is shown in Fig.1. 


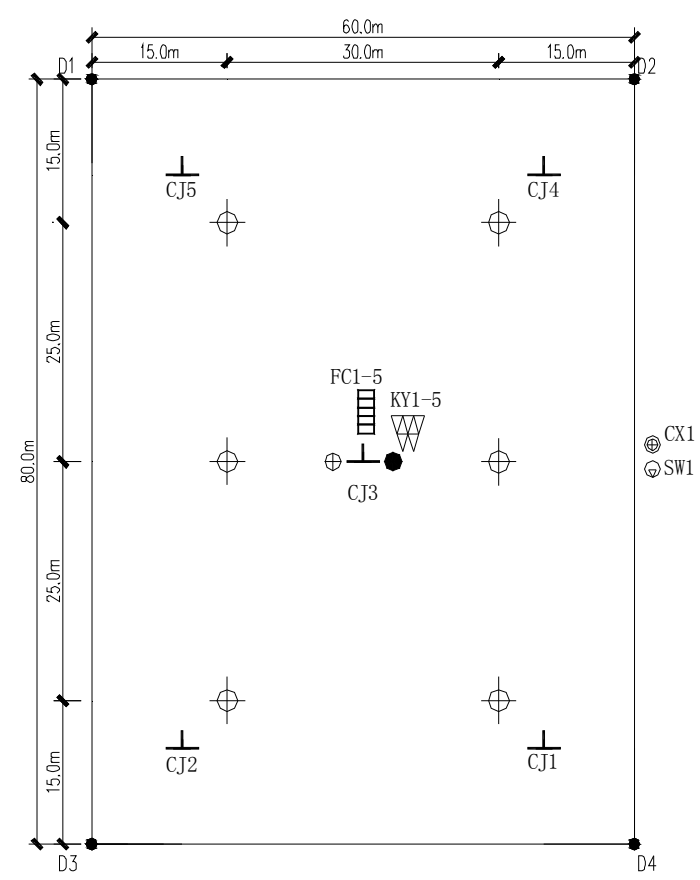

Fig.1. The sketch map of reinforced area

According to the engineering geologic investigation data, the soil in this project is mostly made up of mud, muddy-silty clay and silty clay, the thickness of freshly hydraulic fill is about $3.0 \mathrm{~m}$, and the sediment concentration is high in the lower soli layer of dredger fill. the specific geological conditions are shown in Table 1.

Table 1 Geological conditions

\begin{tabular}{|c|c|c|}
\hline Name of soil layer & $\begin{array}{l}\text { Thickness } \\
{[\mathrm{m}]}\end{array}$ & Soil property description \\
\hline Mud & 3.0 & Gray, rheological plasticity, have peculiar smell \\
\hline Silty clay mixed with sand & 5.1 & $\begin{array}{l}\text { Gray, low-viscosity, mixed with large amount of sediment, } \\
\text { uneven soil }\end{array}$ \\
\hline Silty clay & 2.1 & $\begin{array}{l}\text { Grayish, soft plasticity, contains humus and thin layers of sand, } \\
\text { medium dry strength, medium toughness }\end{array}$ \\
\hline Silty clay & 3.5 & $\begin{array}{l}\text { Grayish-green, plasticity, mixed with large amount of sand, } \\
\text { low-viscosity, medium dry strength, medium toughness }\end{array}$ \\
\hline Silty clay & 2.0 & $\begin{array}{l}\text { Yellowish brown, plasticity, contains rusty spot, mixed with a } \\
\text { small amount of sand, medium dry strength, medium toughness }\end{array}$ \\
\hline Medium sand & 2.3 & $\begin{array}{l}\text { Yellowish brown, medium dense, mainly quartz and feldspar, } \\
\text { graded poor, mixed with a part of clay soil }\end{array}$ \\
\hline
\end{tabular}

Surcharge preloading was adopted to consolidate the foundation of testing area in this project. The specific construction process is as follows: laying $0.5 \mathrm{~m}$ thick sand cushion on the soil surface of testing zone; setting plastic drains; the space of two plastic drains is $0.8 \mathrm{~m}$ and it should be arranged at square; loading hill-skill soil three times at testing zone, and the three loading heights are $1.0 \mathrm{~m}, 1.5 \mathrm{~m}$ and $2.0 \mathrm{~m}$ respectively, the total loading pressure is $89 \mathrm{kPa}$ (including $0.5 \mathrm{~m}$ thick sand cushion).

\section{Consolidation Degree of Soil Mass}

According to monitoring data, the soil mass has been consolidated in the effect of surcharge preloading, and nearly $1.0 \mathrm{~m}$ displacement appeared on the surface, according to Fig.2, all the soil mass within the range of reinforcement depth has consolidation settlement. At the later period, settlement decreased obviously and tends to be stable gradually, which indicated that most of the consolidation settlement can be finished in five months. 


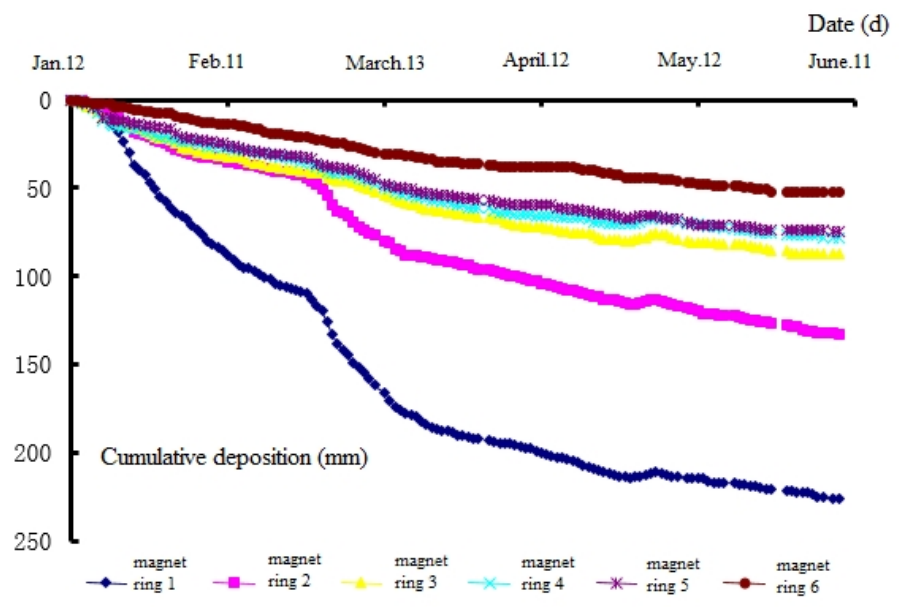

Fig.2 Change curves of layered settlement of FC1-5 at surcharge preloading area

Consolidation degree of soil mass can be calculated by settlement or pore water pressure. Proper drainage measures weren't taken towards the lower soil layer before hydraulic fill carried on, so the effect of consolidation and drainage of silty clay were very common, and this made pore water pressure generated by hydraulic fill fail to release completely in silty clay, and there is part of pore water pressure which can't be quantified remained in the soil, thus, there are large errors in calculate consolidation degree with pore water pressure, and we can only use settlement to calculate consolidation degree. Because the final settlement is needed to calculate consolidation degree, therefore, the empirical hyperbolic method is used in this article to calculate the final settlement of foundation.

Calculating formula of empirical hyperbolic method is as follows:

$$
S_{t}=S_{o}+\frac{t}{\alpha+\beta t}
$$

The following formula is derived by formula (1):

$$
S_{\infty}=S_{o}+\frac{1}{\beta}
$$

Where $t$ is the time from the beginning of full-load, $S_{o}$ is the settlement of foundation full-load, $S_{\infty}$ is the final settlement of foundation, and $\beta$ is a constant correlated with foundation and load.

The following formula can be used to calculated consolidation degree of soil mass after the gain of final settlement:

$$
U_{t}=S_{t} / S_{\infty}
$$

Where $S_{t}$ is the settlement of time t, and $U_{t}$ is consolidation degree of time $\mathrm{t}$.

Based on the observed curves of surface settlement, Table 2 has shown the consolidation degree by formula (2) and formula (3).

Table 2 consolidation degree calculation table after full-load at the testing area

\begin{tabular}{cccccc}
\hline Orientation of settlement point & \multicolumn{2}{c}{ South } & \multicolumn{2}{c}{ Center } & \multicolumn{2}{c}{ North } \\
\hline Settlement points & CJ1 & CJ2 & CJ3 & CJ4 & CJ5 \\
\hline $\mathrm{S}_{\mathrm{O}}$ & 672 & 377 & 520 & 692 & 607 \\
$\beta$ & 0.0039 & 0.0094 & 0.0048 & 0.0024 & 0.0044 \\
$\mathrm{~S}_{\mathrm{t}}$ & 878 & 472 & 691 & 995 & 789 \\
$\mathrm{~S}_{\infty}$ & 928.41 & 483.38 & 728.33 & 1108.67 & 834.27 \\
$\mathrm{~S}_{\text {工后 }}$ & 50.41 & 11.38 & 37.33 & 113.67 & 45.27 \\
$\mathrm{U}_{\mathrm{t}}(\%)$ & 94.57 & 97.65 & 94.87 & 89.75 & 94.57 \\
\hline
\end{tabular}


According to Table 2, the consolidation degree of five surface settlement monitoring points $\mathrm{CJ} 1 \sim \mathrm{CJ} 5$ are all beyond 85\%, and residual settlement after reinforcement was less than 300mm, so the residual settlement consolidation degree and the residual settlement of reinforced soft foundation are all satisfy the requirement of designing when adopting the surcharge preloading.

\section{Vane shear test}

To test the reinforcement effect of foundation, the author carried out vane shear test on the soil before and after reinforcement at the same position, position of testing point is shown in Fig.1, and change process lines of vane strength before and after reinforcement have been shown in Fig.3.

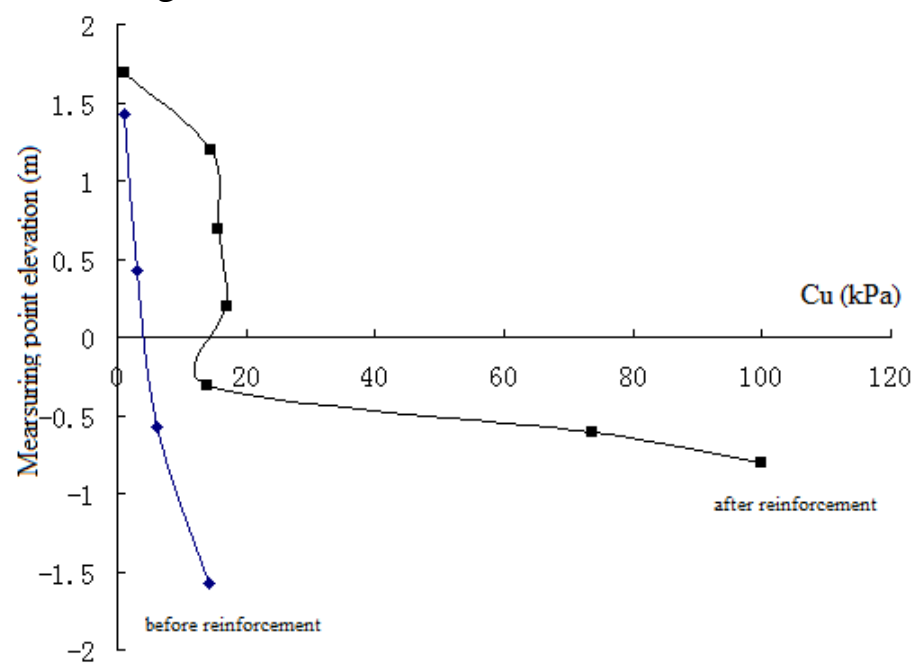

Fig.3 changes curve of vane shear strength before and after reinforcement at testing area

Fig. 3 demonstrates that undrained shear strength of foundation that reinforced with surcharge preloading is increased obviously, especially the hydraulic fill whose surface layer with a thickness of about $3.0 \mathrm{~m}$. So the strength increase of soil below the original ground about $1.0 \mathrm{~m}$ is not obvious, only increased $10 \%$; the strength increase of soil below the original ground about $2.0 \mathrm{~m}$ is obvious, undrained shear strength $\mathrm{Cu}$ increased $423.3 \%$; the strength increase of soil below the original ground about $3.0 \mathrm{~m}$ is more obvious, undrained shear strength $\mathrm{Cu}$ increased $1126.7 \%$, and undrained shear strength $\mathrm{Cu}$ is beyond $100 \mathrm{kPa}$ when vane was pressed below the original ground about $3.5 \mathrm{~m}$, so the strength of soft foundation after reinforcement with surcharge preloading satisfy the requirement of designing .

\section{Comparison of Physical Indexes Before and After Reinforcement}

In order to further reflect the effect of the soft foundation reinforcement, coring operations are needed to carry out the lab geotechnical tests before and after reinforcement at testing points. Thus, we can get the physical indexes of all the soil layers before and after reinforcement, which are shown in Table 3. 
Table 3 Comparative Statistical table of physical and mechanical indexes of soil layers before and after reinforcement at surcharge preloading area

\begin{tabular}{|c|c|c|c|c|c|c|c|c|c|}
\hline \multirow{3}{*}{$\begin{array}{c}\text { Initial } \\
\text { depth } \\
\text { of } \\
\text { sampling } \\
\text { (m) }\end{array}$} & \multirow{3}{*}{$\begin{array}{c}\text { Project } \\
\text { (before } \\
\text { and after } \\
\text { construction) }\end{array}$} & \multirow{3}{*}{$\begin{array}{c}\text { Names of } \\
\text { the soil } \\
\text { sample }\end{array}$} & \multicolumn{3}{|c|}{ Physical properties of soil } & \multicolumn{2}{|c|}{$\begin{array}{c}\text { Consolidated } \\
\text { direct-quick shear }\end{array}$} & \multicolumn{2}{|c|}{ Vertical compression } \\
\hline & & & $\begin{array}{l}\text { Water } \\
\text { content }\end{array}$ & $\begin{array}{c}\text { Dry } \\
\text { density }\end{array}$ & $\begin{array}{l}\text { Void } \\
\text { ratio }\end{array}$ & Cohesion & $\begin{array}{c}\begin{array}{c}\text { Fraction } \\
\text { angle }\end{array} \\
\end{array}$ & $\begin{array}{c}\text { Compression } \\
\text { coefficient }\end{array}$ & $\begin{array}{c}\text { Compression } \\
\text { modulus }\end{array}$ \\
\hline & & & (W) $\%$ & $\left(\rho_{ \pm}\right)\left[\mathrm{g} / \mathrm{cm}^{3}\right]$ & (e) & (c) $[\mathrm{kPa}]$ & $(\boldsymbol{\Phi})^{\circ}$ & $a \mathrm{v}_{1-2}$ & $\mathrm{Es}_{s_{1-2}}$ \\
\hline \multirow{2}{*}{4.8} & Before & Mud & 52.3 & 1.00 & 1.727 & 3.5 & 1.7 & - & - \\
\hline & After & Silty clay & 35.6 & 1.36 & 0.994 & - & - & 0.67 & 3.0 \\
\hline \multirow{2}{*}{7.8} & Before & Silty clay & 32.7 & 1.44 & 0.890 & 5.5 & 22.0 & 0.58 & 3.3 \\
\hline & After & Silt & 20.3 & 1.74 & 0.554 & 11.9 & 25.9 & 0.18 & 8.6 \\
\hline \multirow{2}{*}{9.8} & Before & Silty clay & 24.4 & 1.59 & 0.709 & 13.0 & 22.1 & 0.33 & 5.2 \\
\hline & After & Silt & 19.8 & 1.75 & 0.540 & - & - & 0.17 & 9.0 \\
\hline \multirow{2}{*}{12.8} & Before & Silty clay & 28.7 & 1.52 & 0.786 & 9.0 & 21.0 & 0.46 & 3.9 \\
\hline & After & Silty clay & 30.4 & 1.48 & 0.838 & 9.5 & 22.2 & - & - \\
\hline \multirow{2}{*}{15.8} & Before & Silty clay & 32.0 & 1.44 & 0.890 & 8.5 & 21.0 & 0.56 & 3.4 \\
\hline & After & Silt & 17.3 & 1.83 & 0.473 & - & - & - & - \\
\hline \multirow{2}{*}{17.8} & Before & Silty clay & 25.3 & 1.60 & 0.696 & 12.0 & 22.0 & 0.35 & 4.8 \\
\hline & After & Silty clay & 21.1 & 1.72 & 0.584 & - & - & 0.23 & 6.9 \\
\hline \multirow{2}{*}{18.8} & Before & Silty clay & 23.8 & 1.52 & 0.791 & - & - & 0.33 & 5.5 \\
\hline & After & Silty clay & 23.0 & 1.66 & 0.640 & 17.1 & 22.0 & - & - \\
\hline
\end{tabular}

Notes: Before construction, elevation of soil hole is $2.428 \mathrm{~m}$, and after construction, elevation of soil hole is $6.191 \mathrm{~m}$.

According to the Table 3, the water content, void ratio and compressibility of soft foundation decreased obviously, strength index and compression modulus increased obviously. And it indicates that the effect of surcharge preloading reinforcement is obvious, it can improve physical and mechanical indexes of soil greatly, and it also satisfies the requirement of bearing capacity after construction.

\section{Conclusions}

In this project, the reinforcement effect is proved to be more ideal by field monitoring and date analysis, and the conclusions are as followed:

(1) Surcharge preloading is an effective method to reinforce the soft foundation in Dalian area.

(2) According to the analysis of lab geotechnical tests and vane shear test, using the surcharge preloading to reinforce the soft foundation of Dalian area can improve physical and mechanical indexes of soil greatly, besides, it can also improve shear strength of soft foundation effectively, thus improve the bearing capacity of soft foundation, eventually decrease the after- settlement of the field effectively.

(3) Reinforcing the soft foundation of Dalian area with surcharge preloading fully meets design requirements, and it has reference values to deal with soft foundation under similar geologic conditions at that place.

\section{References}

[1] Technical Specification of Prototype Observation for Water Transport Engineering Hydrostructure, JTJ 218-2005.

[2] Tian Zhong. (2007) Construction Technique of Using Vacuum Preloading to Consolidate Soft-soil Foundation, Railway Engineering (in Chinese).

[3] ZHAO Hui, LI Liang-gang. (2005)The Consolidation Degree Of Using Load Pre-pressing Drainage Consolidation Method to Consolidate Soft-soil Foundation, Exploration Engineering, no. 3 (in Chinese). 
[4] GUO Dian-ta, ZHENG Jian-hong. (2005)Design Method for Consolidation of Heap and Vacuum Preloading, Acta Agriculturae Universitatis Jiangxiensis, vol. 27, no. 4 (in Chinese).

[5] Zhen Xin-yang, Xu Feng, (2004)Application Comparison of Vacuum Preloading and Surcharge Preloading in Dealing With Super-soft Soil Foundation of Huanghua Port, Journal of Beijing Communications Management Institute for Executives, vol. 14, no. 1 (in Chinese).

[6] XU Guo-ping. (2009)Analysis of Vacuum Stow Combining Pre-pressing Method Reinforcing Shoal Soft Foundation, Foundation Engineering Testing and Monitoring, vol. 27, no. 8 (in Chinese). 